\title{
Evaluasi Pemakaian Antibiotik Profilaksis Ceftriaxone Injeksi dan Cefadroxil Oral Terhadap Penyembuhan Luka Post Sectio Caesarea
}

\author{
Ivanna Beru Brahmana ${ }^{1}$, Ika Setyawati ${ }^{2}$ \\ 1. Departemen Obstetri dan Ginekologi, Program Studi Pendidikan Dokter, Fakultas \\ Kedokteran dan Ilmu Kesehatan, Universitas Muhammadiyah Yogyakarta \\ 2. Departemen Biokimia, Program Studi Pendidikan Dokter, Fakultas Kedokteran dan \\ Ilmu Kesehatan, Universitas Muhammadiyah Yogyakarta
}

Korespondensi: dr.ikasetyawati@yahoo.co.id, ikasetyawati.dr@umy.ac.id

\begin{abstract}
ABSTRAK
Pendahuluan: Penyembuhan luka operasi sectio caesarea (SC) yang baik sangat diharapkan oleh setiap pasien dan dokter. Pemilihan antibiotik yang tepat dibutuhkan dalam penyembuhan luka operasi. Ceftriaxone injeksi merupakan antibiotik spektrum luas yang banyak dipakai sebagai antibiotik profilaksis $S C$. Cefadroxil oral dipilih sebagai antibiotik yang diberikan pada pasien post operasi SC. Penelitian ini bertujuan menilai efektifitas pemakaian ceftriaxone injeksi dan cefadroxil oral pada penyembuhan luka operasi post $S C$. Metode: Data diambil dari rekam medis pasien selama tiga tahun (tahun 2016-2018) pada saat kontrol di dokter praktek swasta di Klaten, Jawa Tengah. Kriteria inklusi adalah pasien yang menjalani operasi $S C$, hamil aterm, dan tidak menderita DM. Waktu kontrol antara dua sampai dengan tujuh hari setelah operasi $S C$. Data diolah secara deskriptif.

Hasil: Didapatkan 73 subjek penelitian yang memenuhi kriteria inklusi. Waktu kontrol dua hari post SC didapatkan sebanyak $23,3 \%$ (17/73), tiga hari post SC sebanyak 21,9\% (16/73), empat hari post SC sebanyak 23,3\% (17/73), lima hari post SC sebanyak $21,9 \%$ (16/73), enam hari post SC sebanyak 2,7\% (2/73), dan tujuh hari post SC sebanyak 6,8\% $(5 / 73)$. Kejadian luka infeksi ditandai dengan keluarnya cairan bernanah dari luka bekas operasi SC. Kejadian luka infeksi terjadi sebanyak 5,5\% (4/73). Kejadian luka infeksi terjadi pada pasien yang kontrol pada hari kedua sebanyak tiga kasus dan kontrol pada hari keempat sebanyak satu kasus.

Kesimpulan: Ceftriaxone injeksi dan cefadroxil oral efektif memberikan kesembuhan pada luka operasi post $S C$.
\end{abstract}

Kata kunci: ceftriaxone injeksi, cefadroxil, luka sectio caesarea.

ABSTRACT

Introduction: Good healing of caesarean section (CS) wound is highly expected by every patient and doctor. Selection of the right antibiotic is needed in healing wound surgery. Ceftriaxone injection and oral cefadroxil are widely used in CS prophylactic antibiotics. This study was to assess the effectiveness of the use of injection ceftriaxone and oral cefadroxil in wound healing in post CS.

Methods: Data were collected from a patient's medical record for three years (2016-2018) at the time of control at a private practice doctor in Klaten, Central Java. Inclusion criteria were patients who underwent CS, term pregnant, and didn't have DM. The control time is between two to seven days after CS. Data processed descriptively.

Results: There were 73 study subjects who met the inclusion criteria. The control time of two days post CS was $23.3 \%$ (17/73), three days post CS were $21.9 \%$ (16/73), four days post CS were $23.3 \%$ (17/73), five days post CS were $21.9 \%$ (17/73) $16 / 73$ ), six days post CS were $2.7 \%$ (2/73), and seven days post CS were $6.8 \%$ (5/73). The incidence of infection wounds is characterized by discharge of festering fluid from CS scars. The incidence of 
Brahmana \& Setyawati ., Evaluasi Pemakaian Antibiotik Profilaksis Ceftriaxone Injeksi dan Cefadroxil Oral Terhadap Penyembuhan Luka Post Sectio Caesarea

infection wounds occurs as much as $5.5 \%$ (4/73), who occurred in patients who were control on day two in three cases and controls on day four in one case.

Conclusion: Ceftriaxone injection and oral cefadroxil are effective in healing postoperative wound healing.

Keywords: ceftriaxone injection, cefadroxil, sectio caesarea wound.

\section{PENDAHULUAN}

Operasi sesar atau sectio caesarea (SC) merupakan jenis operasi laparotomi yang ditujukan untuk melahirkan janin perabdominal. Laparotomi adalah suatu jenis tindakan operasi/pembedahan dengan membuat sayatan/membuka dinding abdomen ${ }^{1}$. Penyembuhan luka operasi $S C$ yang baik akan menurunkan morbiditas dan mortalitas ibu bersalin. Kejadian luka infeksi sebagai komplikasi post SC akan meningkatkan lama tinggal di rumah sakit dan merupakan penyebab morbiditas pada ibu bersalin. Luka infeksi post $S C$ ditandai dengan timbulnya demam, keluar cairan dari bekas operasi $S C$, endometritis, bakteriemia, dan infeksi saluran kemih ${ }^{2}$.

Infeksi Luka Operasi (ILO) adalah infeksi pada kulit, jaringan subkutis dan organ yang mendapat manipulasi operasi dan terjadi dalam 30 hari setelah tindakan atau dalam satu tahun pada tindakan pemasangan orthopedic implant $^{3}$. Untuk itu diperlukan antibiotika spektrum luas yang menyebabkan lapisan demi lapisan sayatan operasi sembuh dan terhindar dari infeksi.

Pencegahan terjadinya luka infeksi pada penyembuhan luka post $S C$ dapat dilakukan dengan cara pemberian antibiotik profilaksis. Antibiotik profilaksis diberikan sebelum operasi SC dilakukan, diharapkan penyembuhan luka operasi tidak terjadi infeksi post $S C^{2}$. Era pembiayaan yang di tanggung asuransi saat ini, antibiotik profilaksis yang dipilih adalah ceftriaxone injeksi dan cefadroxil oral. Ceftriaxone injeksi diberikan hanya sekali, 30 menit sebelum operasi $S C$. Cefadroxil oral diberikan selama lima hari setelah tindakan operasi $S C$. Ceftriaxone injeksi atau cefotaxime injeksi sebagai antibiotik profilaksis operasi $S C$ juga digunakan di RS Dr. Iskak, Tulungagung. Antibiotik oral selama lima hari diberikan setelah tindakan $S C^{4}$.

Pemberian antibiotika profilaksis sebelum memulai tindakan operasi sesar merupakan hal yang dianjurkan. Bila terdapat infeksi, maka diberikan pemberian antibiotika terapeutik, untuk penyembuhan infeksinya ${ }^{5}$. Jenis antibiotik profilaksis dan terapi terbanyak yang dipilih pada tindakan SC elektif dari penelitian Prasetya D.B. adalah sefotaksim $(66,21 \%)^{6}$. Penelitian lain tentang penggunaan antibiotik pada tindakan seksio sesarea adalah ampisilin/sulbaktam (37\%), sefuroksim (34\%), seftriakson (24\%), sefazolin (5\%), metronidazol (1\%), dan gentamisin $(1 \%)^{7}$

Studi tentang efektifitas penggunaan antibiotik profilaksis ceftrixone injeksi dilanjutkan cefadroxil oral pada post $S C$ yang melakukan kontrol pada dokter praktek swasta di Klaten belum pernah dilakukan. Pasien yang mendapatkan pelayanan operasi di rumah sakit dalam era pembiayaan yang di tanggung asuransi ini berhak untuk melanjutkan penanganan post operasinya pada dokter praktek swasta. Hal tersebut melatarbelakangi peneliti untuk melakukan evaluasi tentang efektifitas penggunaan antibiotik profilaksis ceftriaxone injeksi dilanjutkan cefadroxil oral pada penyembuhan luka operasi SC yang kontrol di tempat praktek dokter swasta. 
Brahmana \& Setyawati ., Evaluasi Pemakaian Antibiotik Profilaksis Ceftriaxone Injeksi dan Cefadroxil Oral Terhadap Penyembuhan Luka Post Sectio Caesarea

\section{METODE}

Jenis penelitian ini adalah observasional dengan cross sectional design untuk mengevaluasi pemakaian antibiotik profilaxis ceftriaxone injeksi dan cefadroxil oral sebagai terapi post $S C$ terhadap penyembuhan luka operasi.

Subjek penelitian adalah perempuan yang telah menjalani operasi SC dengan menggunakan antibiotika profilaksis ceftriaxone injeksi dilanjutkan cefadroxil oral dan melakukan kontrol penyembuhan luka operasi SC ke Fasilitas Pelayanan Kesehatan Primer Praktek Dokter Swasta di Klaten, Jawa Tengah, dengan kriteria Inklusi: Perempuan post operasi $S C$ atau re-SC, hamil aterm, tidak menderita Diabetes Mellitus (DM), mendapatkan antibiotika profilaksis ceftriaxone injeksi, diberikan 30 menit sebelum $S C$ atau re-SC, dan hanya diberikan 1x. Selanjutnya mendapatkan antibiotika cefadroxil oral, $3 \times 500 \mathrm{mg}$, selama 5 hari, yang diberikan setelah operasi $S C$ atau re-SC. Kriteria Eksklusi adalah: a. perempuan post operasi $S C$ atau re-SC yang alergi dengan antibiotika profilaksis ceftriaxone injeksi; $b$. perempuan post operasi $S C$ atau re-SC yang alergi dengan antibiotika cefadroxil oral. Penelitian ini dilaksanakan setelah memperoleh persetujuan etik (No: 207/ECKEPK FKIK UMY/X/2019).

Pengambilan data dari rekam medis pasien dalam kurun waktu Januari 2016 Desember 2018. Data diolah dan dianalisis univariat dengan menggunakan SPPS (Version 15.0). Penentuan jumlah subjek penelitian menggunakan persamaan berikut ${ }^{8}$ :

$n=\frac{Z^{2} p(1-p)}{d^{2}}$

$\mathrm{n}=38,146$

Variabel dependent dalam penelitian ini adalah penyembuhan luka operasi $S C$ atau re$S C$, dan variabel independent adalah pemakaian antibiotik ceftriaxone injeksi dan cefadroxil oral.

\section{HASIL}

Total subjek penelitian sesuai dengan kriteria inklusi dan eksklusi (73 responden). Waktu kontrol dua hari post SC didapatkan sebanyak $23.3 \%$ (17/73), tiga hari post SC sebanyak $21.9 \%$ (16/73), empat hari post SC sebanyak $23.3 \%$ (17/73), lima hari post SC sebanyak $21.9 \%$ (16/73), enam hari post $S C$ sebanyak $2.7 \%$ (2/73), dan tujuh hari post $S C$ sebanyak $6.8 \%(5 / 73)$ terlihat pada tabel 1 . Pasien kontrol kembali ke dokter praktek swasta paling banyak kontrol di hari kedua dan keempat post SC. Hal ini mungkin sebagai gambaran bahwa pasien ingin memastikan bahwa luka operasi mereka dalam kondisi aman dan baik, sebelum mereka berada di rumah.

Tabel 1. Durasi Lama Waktu Kontrol post SC

\begin{tabular}{cc}
\hline Durasi (hari) & Percentage (\%) \\
\hline 2 & 23.3 \\
3 & 21.9 \\
4 & 23.3 \\
5 & 21.9 \\
6 & 2.7 \\
7 & 6.8 \\
\hline
\end{tabular}

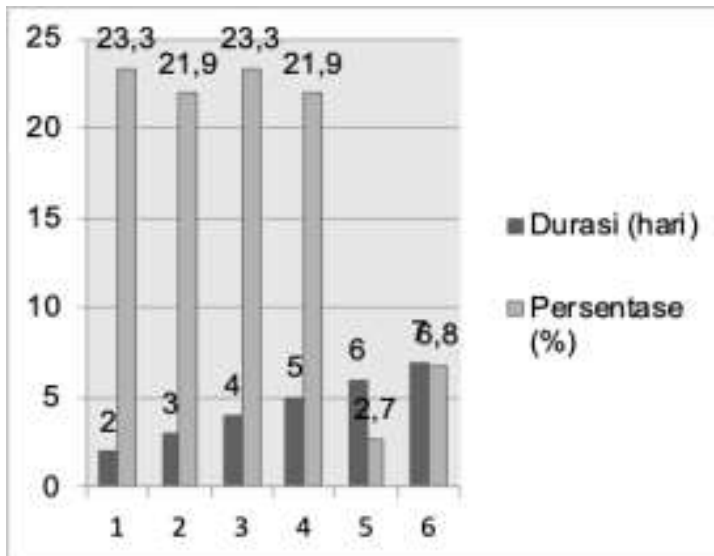

Gambar 1. Durasi Lama Waktu Kontrol post SC 
Brahmana \& Setyawati ., Evaluasi Pemakaian Antibiotik Profilaksis Ceftriaxone Injeksi dan Cefadroxil Oral Terhadap Penyembuhan Luka Post Sectio Caesarea

Tabel 2. Kualitas Penyembuhan Luka Operasi SC

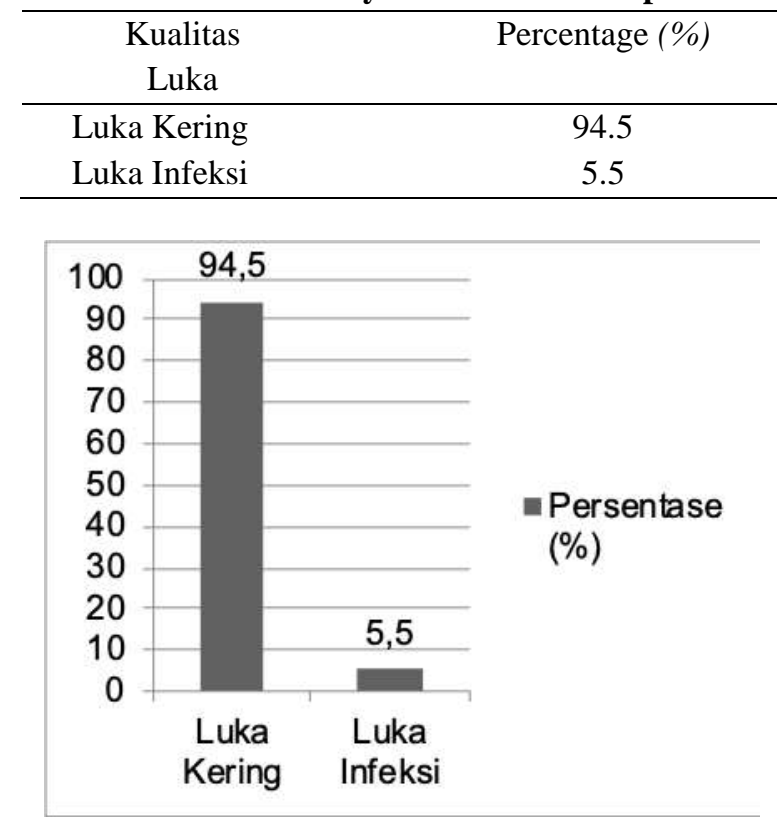

Gambar 2. Kualitas Penyembuhan Luka Operasi SC

\section{PEMBAHASAN}

Dalam rangkaian perawatan operatif, pemakaian antibiotika profilaksis merupakan hal yang dianjurkan'. Ceftriaxone injeksi sebagai antibiotika spektrum luas, antibiotika golongan sefalosporin generasi ketiga diberikan dengan suntikan intravena dan cefadroxil oral menjadi pilihan antibiotika profilaksis dalam era pembiayaan yang di tanggung asuransi di Indonesia saat ini ${ }^{10,11}$.

Harga obat ceftriaxone injeksi yang cukup murah menjadi salah satu pilihan cost effective dari segi pembiayaan yang di tanggung asuransi. Lama perawatan post operasi $S C$ bagi pasien yang dibiayai oleh asuransi adalah dua hari perawatan. Selanjutnya pasien diminta untuk kontrol kembali, setelah diberikan informasi perawatan post operasi $S C$ selama di rumah. Pasien dianjurkan kontrol kembali ke rumah sakit, namun juga diijinkan untuk kontrol ke tempat praktek dokter swasta sebagai pemenuhan hak mendapatkan pelayanan kesehatan bagi pasien.
Kualitas luka operasi dinilai dengan pemeriksaan penyembuhan luka post operasi $S C$ atau post re-SC dilakukan dengan prosedur sebagai berikut: membuka verban penutup luka operasi $S C$ atau post re-SC; menilai penyembuhan luka setelah verban dibuka. Apabila tidak tampak keluar cairan, tidak bernanah, tidak berbau, tidak didapatkan kulit bekas operasi yang bengkak, kemerahan, dan tidak terasa nyeri, maka luka operasi dinyatakan sembuh dan disebut luka kering. Apabila tampak keluar cairan, bernanah, berbau, didapatkan kulit bekas operasi yang bengkak, kemerahan, dan terasa nyeri, maka luka operasi dinyatakan sebagai bernanah dan berbau serta disebut luka infeksi. Apabila saat membuka verban bekas operasi $S C$ atau re-SC tidak ditemukan cairan, dan luka dikatakan menyembuh, maka antibiotika yang digunakan dinyatakan efektif ${ }^{5}$.

Kualitas penyembuhan luka operasi $S C$ berupa luka kering dan luka infeksi. Luka kering didapatkan sebanyak 69 (94.5\%) orang dan luka infeksi didapatkan sebanyak 4 (5.5\%) orang. Kejadian luka infeksi terjadi pada pasien yang kontrol pada hari ke-dua sebanyak tiga kasus (3/73) dan kontrol pada hari keempat sebanyak satu kasus (1/73) terlihat pada tabel 2.

Komplikasi umum paska operasi adalah infeksi luka sehingga berdampak terhadap penambahan lamanya waktu perawatan, peningkatan biaya dan morbiditas ibu ${ }^{12}$. Kejadian luka infeksi terjadi pada pasien yang kontrol pada hari kedua dan keempat, dan justru luka infeksi pun terjadi pada pasien yang kontrol pada hari tersebut. Hal ini menunjukkan kemungkinan saat luka operasi dinilai di rumah sakit dan dinyatakan luka baik atau luka kering, namun karena adanya keluhan nyeri atau hal yang kurang nyaman bagi pasien, maka pasien segera datang kontrol untuk memastikan bahwa luka operasi SC mereka dalam keadaan baik.

Namun hal-hal yang dipertimbangkan oleh pasien terhadap kesembuhan luka operasi 
Brahmana \& Setyawati ., Evaluasi Pemakaian Antibiotik Profilaksis Ceftriaxone Injeksi dan Cefadroxil Oral Terhadap Penyembuhan Luka Post Sectio Caesarea

mereka tidak dibahas dalam penelitian ini. Yang dinilai adalah bagaimana penyembuhan luka operasi post SC yang terlihat dengan adanya luka bernanah atau tidak.

Kejadian luka infeksi pada penelitian ini sebesar 5.5\% (4/73) menunjukkan bahwa pemberian ceftriaxone injeksi yang diberikan 30 menit sebelum operasi $S C$ dan hanya diberikan sebanyak satu kali pemberian, dan dilanjutkan dengan pemberian cefadroxil oral selama lima hari efektif memberikan penyembuhan luka operasi $S C$. Hal tersebut sejalan dengan hasil penelitian oleh Raghunath Shinde tahun 2015 bahwa tingkat kegagalan pemberian antibiotik ceftriaxone profilaksis tunggal pada pasien SC adalah 2.0\% (1 dari 50 orang) sehingga dapat dikatakan efektif dalam pencegahan morbiditas ibu.

Kumari et,al. (2017) menyatakan bahwa tidak ada morbiditas infeksi yang signifikan dalam penelitian, dan menemukan bahwa Ceftriaxone (dosis tunggal) efektif dalam pencegahan komplikasi infeksi pasca caesar ${ }^{13}$.

Antibiotik dosis tunggal terbukti lebih ekonomis. Tinjauan aspek ekonomi oleh Chelmow (2004) mengungkapkan penurunan yang signifikan dalam keseluruhan biaya pengobatan (30 \$) pada kelompok studi. Ceftriaxone profilaksis lebih hemat biaya untuk perawatan pasien ${ }^{13,14}$. Harga obat ceftriaxone injeksi dan cefadroxil oral yang cukup murah menunjang kebutuhan cost effective dalam pembiayaan yang di tanggung asuransi di Indonesia seperti saat ini.

Pilihan antibiotika yang digunakan untuk operasi SC di RS Pekanbaru Medical Center (PMC) adalah ceftriaxone tunggal dosis $1 \mathrm{~g}$ sebanyak 43 orang (58.9\%) dan kombinasi gentamisin $(80 \mathrm{mg})$ dengan ceftriaxone $(1 \mathrm{~g})$ sebanyak 30 orang $(41.1 \%)$. Antibiotika yang digunakan tersebut kategori generik (100\%), waktu pemberian 0-2 jam pra-operasi (100\%), dan diberikan secara intravena $(100 \%)^{15}$.

Antibiotika profilaksis pada tindakan operasi diberikan dengan tujuan mencegah terjadinya infeksi luka ${ }^{16}$. Risiko terjadinya infeksi post operasi $S C$ lebih rendah terjadi pada pasien yang diberikan antibiotik profilaksis satu jam preinsisi (RR O,77; 95\% CI 0,62-0,97). Kejadian endometritis berkurang pada kelompok yang diberi antibiotik profilaksis preinsisi (RR 0,62; 95\% CI 0,39-0,99; $\mathrm{P}$ value 0,036$)^{17}$.

Pemakaian ceftriaxone dan metroniodazole sebagai antibiotika profilaksis yang diberikan satu kali sebelum tindakan operasi mempunyai keefektifan yang sama dibandingkan dengan pemakaian antibiotika yang diberikan berulang, dalam mencegah terjadinya infeksi pada tindakan operasi $S C$ elektif ${ }^{18}$

Pasien yang mendapatkan pelayanan operasi di rumah sakit dengan menggunakan fasilitas pembiayaan yang di tanggung asuransi sebagian besar melakukan kontrol kembali di rumah sakit tersebut. Sebagian kecil pasien yang melakukan kontrol post SC di tempat praktek dokter swasta. Hal tersebut merupakan hak pasien untuk mendapatkan pilihan tempat pelayanan kesehatan. Sedikitnya pasien yang melakukan kontrol di tempat praktek dokter swasta merupakan kelemahan dalam penelitian ini, sehingga jumlah subyek penelitian diutamakan memenuhi jumlah sampel yang diperlukan.

\section{KESIMPULAN}

Ceftriaxone injeksi dan cefadroxil oral sebagai antibiotik profilaksis operasi $S C$ dengan sistem pembiayaan yang di tanggung asuransi ini pada pasien kontrol luka post SC di tempat praktek dokter swasta di Klaten, secara deskriptif menunjukkan bahwa dari 73 subyek, didapatkan 4 (5.5\%) subyek yang mengalami luka infeksi sehingga ceftriaxone injeksi dan cefadroxil oral generik efektif memberikan penyembuhan luka operasi post $S C$. 
Brahmana \& Setyawati ., Evaluasi Pemakaian Antibiotik Profilaksis Ceftriaxone Injeksi dan Cefadroxil Oral Terhadap Penyembuhan Luka Post Sectio Caesarea

\section{UCAPAN TERIMA KASIH}

Tidak ada sponsor dalam pelaksanaan penelitian ini.

\section{DAFTAR PUSTAKA}

1. Purbadi S., \& Husodo L. Prinsip-prinsip Pembedahan Ginekologi. Dalam: Ilmu Kandungan. Ed 3. Jakarta: P.T. Bina Pustaka Sarwono Prawirohardjo. 2017

2. Kumari R., Sharma A., Sheetal, Roy P., Anupriya. To study the effectiveness of prophylactic use of ceftriaxone (single dose) in caesarean section in low risk patients in a tertiary care center, Moradabad, India. Int J Res Med Sci. 2017 Dec, 5(12): 5278-82

3. Seni, et al., Antimicrobial resistance in hospitalized surgical patients: a silently emerging public health concern in Uganda. BMC Research Notes, 2013: 6(298):1-7.

4. Muzayyanah B., Yulistiani, Hasmono D., Wisudani N. Analysis of Prophylactic Antibiotics Usage in Caesarean Section Delivery. Fol Med Indones. September 2018, 54(3): 161-6.

5. Waspodo D. Perawatan Operatif. Dalam: Ilmu Kebidanan. Ed. 4. Jakarta: P.T. Bina Pustaka Sarwono Prawirohardjo. 2016

6. Prasetya D.B. Efektifitas Penggunaan Antibiotik Pada Pasien Seksio Sesarea Elektif di Rumah Sakit X Sidoarjo. Calyptra: Jurnal Ilmiah Mahasiswa Universitas Surabaya, Vol 2 No.2.

7. Yulia R., Herawati F., Jaelani A.K., Anggraini W. Evaluasi Penggunaan Antibiotik dan Profil Kuman pada Seksio Sesarea di Rumah Sakit Umum Daerah Kabupaten Pasuruan. Jurnal Farmasi Klinik Indonesia, 2018: 7(2):69-77.

8. Lemeshow, S., Besar Sampel dalam Penelitian Kesehatan. Terjemahan Adequazy of Sample Size in Health Studies, oleh Dibyo Pramono. Yogyakarta : Gadjah Mada University Press. 1997.

9. Ahmad ET, Mirghani OA, Gerais AS, Adam I. Ceftriaxone versus ampicillin/ cloxacillin as antibiotic prophylaxis in elective caesarean section. East Mediterr Health J 2004; 10(3): 277-288.

10. Cefadroxil.https://www.medicinenet.com/cefad roxil-oral/article.htm.

11. Ceftriaxone.http://www.mipafarmasi.com/2016/05/ceftriaxone.html.

12. Raghunath Shinde, Rahul Shah, Sudhir Bhave, Smita Bhat. "Study of Ceftriaxone versus Multiple Drugs in Caesarean Section". Journal of Evolution of Medical and Dental Sciences 2015; Vol. 4, Issue 08, January 26; Page: 13191324, DOI: $10.14260 /$ jemds $/ 2015 / 185$ cit Owen J. Wound complications after caesarean section. COG 1994; 37(4): 842-855.

13. Kumari R, Sharma A, Sheetal, Roy P, Anupriya. To study the effectiveness of prophylactic use of ceftriaxone (single dose) in caesarean section in low risk patients in a tertiary care center, Moradabad, India. Int J Res Med Sci 2017;5:5278-82.

14. Chelmow D, Hennesy M, Evantash EG. Prophylactic antibiotics for non-laboring patients with intact membranes undergoing caesarean delivery: an economic analysis. Am J Obstet Gynaecol 2004; 191: 1661-1665.

15. Husnawati dan Wandasari F. Pola Penggunaan Antibiotik Profilaksis pada Pasien Bedah Caesar (Sectio Caesarea) di Rumah Sakit Pekanbaru Medical Center (PMC) Tahun 2014. Jurnal Sains Farmasi \& Klinis, 2016: 2(2): 3037.

16. Parulekar P, Kumar S, Awasthi RT, Tarneja P. A single dose of cefotaxime- as a prophylaxis during caesarean section. J Obstet Gynaecol Ind 2001. Sept/Oct; 51(5): 118-121.

17. Dlamini, et al., Antibiotic prophylaxis for caesarean section at a Ugandan hospital: a randomised clinical trial evaluating the effect of administration time on the incidence of postoperative infections. BMC Pregnancy and Childbirth, 2015: 15(91): 1-7.

18. Mugisa G.A., Kiondo P., Namagembe I. Single dose ceftriaxone and metronidazole versus multiple doses for antibiotic prophylaxis at elective caesarean section in Mulago hospital: A randomized clinical trial. AAS Open Research, 2018: 1(11):1-12. 